University of Nebraska - Lincoln

DigitalCommons@University of Nebraska - Lincoln

1996

\title{
The Influence of Land Use/Land Cover on Climatological Values of the Diurnal Temperature Range
}

\author{
Kevin P. Gallo \\ National Climatic Data Center, Kevin.P.Gallo@noaa.gov \\ David R. Easterling \\ National Climatic Data Center \\ Thomas C. Peterson \\ National Climatic Data Center
}

Follow this and additional works at: https://digitalcommons.unl.edu/natrespapers

Part of the Natural Resources and Conservation Commons

Gallo, Kevin P.; Easterling, David R.; and Peterson, Thomas C., "The Influence of Land Use/Land Cover on Climatological Values of the Diurnal Temperature Range" (1996). Papers in Natural Resources. 191.

https://digitalcommons.unl.edu/natrespapers/191

This Article is brought to you for free and open access by the Natural Resources, School of at DigitalCommons@University of Nebraska - Lincoln. It has been accepted for inclusion in Papers in Natural Resources by an authorized administrator of DigitalCommons@University of Nebraska - Lincoln. 
JOURNAL OF CLIMATE 9 (1996), pp. 2941-2944.

This article is a U.S. government work, and is not subject to copyright in the United States

NOVEMBER 1996

NOTES AND CORRESPONDENCE

2941

\title{
The Influence of Land Use/Land Cover on Climatological Values of the Diurnal Temperature Range
}

\author{
Kevin P. Gallo \\ Office of Research and Applications, NOAA/NESDIS, Washington, D.C. \\ David R. Easterling and Thomas C. Peterson \\ Global Climate Laboratory, National Climatic Data Center, Asheville, North Carolina
}

25 January 1996 and 24 April 1996

\begin{abstract}
The diurnal temperature range (DTR) at weather observation stations that make up the U.S. Historical Climatology Network was evaluated with respect to the predominant land use/land cover associated with the stations within three radii intervals $(100,1000$, and $10000 \mathrm{~m})$ of the stations. Those stations that were associated with predominantly rural land use/land cover (LULC) usually displayed the greatest observed DTR, whereas those associated with urban related land use or land cover displayed the least observed DTR. The results of this study suggest that significant differences in the climatological DTR were observed and could be attributed to the predominant LULC associated with the observation stations. The results also suggest that changes in the predominant LULC conditions, within as great as a $10000 \mathrm{~m}$ radius of an observation station, could significantly influence the climatological DTR. Future changes in the predominant LULC associated with observation sites should be monitored similar to the current practice of monitoring changes in instruments or time of observation at the observations sites.
\end{abstract}

\section{Introduction}

The National Climatic Data Center conducted a survey in 1990 of "First Order" and "Historical Climatology Network" (HCN) weather observation stations in the United States to determine the land use/land cover near the stations. This survey was conducted in response to an initiative by the World Meteorological Organization to enhance station history information associated with a Global Baseline Dataset Project (WMO 1990 ). Weather station observers associated with each station were asked to select from nine categories the predominant land use/land cover (LULC) within 100, 1000 , and 10000 meter radii of the location of the station.

The influence of urbanization on climate data has been well documented (e.g., Landsberg 1981; Kukla et al. 1986; Karl et al. 1988; Changnon 1992; Gallo et al. 1993). The information collected in the 1990 survey of HCN stations (NOAA 1996) permits a more general analysis of the influence of LULC on climate variables. The objectives of this study were to explore the effects of land use/land cover associated with the $\mathrm{HCN}$ observation stations on the diurnal range of observed air temperatures.

Corresponding author address: Kevin P. Gallo, National Climatic Data Center, 151 Patton Ave., Asheville, NC 28801-5001.

\section{Methodology}

The U.S. HCN serial temperature and precipitation dataset represents "the best available data from the United States for analyzing long-term climate trends on a regional scale" (Karl et al. 1990). The dataset is updated periodically and includes monthly temperature data that have been adjusted to remove biases caused by changes in the time of observation, changes in instruments, movement of weather stations, and urbanization. The HCN dataset is available in several versions that include no adjustments, one or more of the adjustments, or all of the adjustments. The data utilized in this study included adjustments for changes in time of observation, changes in instruments, and movement of weather stations. The urbanization adjustments were not utilized in this study as several of the LULC classes being evaluated could be considered as urban. The HCN network currently includes 1221 stations, of which, LULC information was obtained for 1219 of the stations.

The temperature variable selected for analysis was the diurnal temperature range $(\mathrm{DTR}=$ maximum - minimum temperature). The DTR was selected to minimize the regional variation that would be present in an analysis of either maximum or minimum temperature over the entire United States. The 1995 update of the U.S. HCN dataset was utilized for this analysis. Monthly DTR was computed for each of the U.S. HCN 
TABLE 1. Land use/land cover classes included in the survey of the $\mathrm{HCN}$ stations.

\begin{tabular}{cl}
\hline \hline Class & \multicolumn{1}{c}{ Land use/land cover } \\
\hline 0 & unknown \\
1 & nonvegetated or barren \\
2 & coastal or island \\
3 & forest \\
4 & farmland, savannah, prairie, or tundra \\
5 & small town $(<1000$ population) \\
6 & town (1000 to 10000 population) \\
7 & small city (city with buildings $<10 \mathrm{~m}$ tall) \\
8 & large city (city with buildings $>10 \mathrm{~m}$ tall) \\
9 & airport \\
\hline
\end{tabular}

stations from the available monthly maximum and minimum temperatures for the ten-year interval of 1981 1990.

Generally, as the sampled radius increased from 100 to $10000 \mathrm{~m}$ the number of predominant LULC classes listed on the surveys increased. Stations that had more than one predominant LULC type within a radius level were excluded from the analysis in an effort to maintain a single predominant class per radius. The number of stations included in the analysis varied from year-toyear, however, was minimally 1000, 835, and 697 for the 100,1000 , and $10000 \mathrm{~m}$ radii, respectively.

The land use/land cover classes (Table 1) include several classes related to urbanized areas. While the classes included in the survey (e.g., class number 4) may be too general for some applications, major differences in LULC are differentiated. Those stations that had a LULC designation of "unknown" were not included in the analysis.

While the use of DTR does minimize the influence of regional differences compared to maximum or minimurn temperatures, regional differences (e.g., the arid U.S. Southwest compared to the humid U.S. Southeast) may still influence the DTR. Thus, the HCN stations were aggregated into one of 23 climate regions defined by Karl et al. (1988). Within each climate region a LULC class was required to be represented by a minimum of two stations, and that condition met, the station DTR data were averaged for each LULC for further analysis. The DTR values for each station were then evaluated for the winter (mean DTR for months of Dec, Jan, and Feb), summer (Jun, Jul, and Aug), and annually. Differences in the seasonal and annual DTR associated with the predominant land use/land cover types were evaluated for each of the three radii included in the survey.

\section{Results and discussion}

a. General

Comparisons of DTR for all LULC classes within each climate region were not possible as several of the climate regions did not include the required minimum of two stations per LULC class. All of the climate regions included at least two stations with a predominant LULC of farmland within $100 \mathrm{~m}$ of the station, however, less than $40 \%$ included stations with a predominant LULC of barren, coastal, or large city. All LULC classes other than coastal or barren were observed as predominant within a $1000-\mathrm{m}$ radius of the stations in over $60 \%$ of the climate regions. Forest, farmland, town, small and large cities were the predominant classes within a $10000-\mathrm{m}$ radius of the stations in over $60 \%$ of the climate regions. The greatest and least observed DTR values per climate region and their associated LULC classes (e.g., Table 2), that were found significantly different ( $\alpha==.05$; Tukey's studentized range test), were utilized in subsequent analyses.

\section{b. Seasonal and annual variation in DTR}

The DTR observed during the summer months was larger than the winter months, for both the greatest and least observed values within the climate regions (Table 3 ). These seasonal differences in DTR are likely due to the seasonal differences in cloud cover and insolation.

The difference between the least and greatest observed annual DTR was computed for each of the three intervals and radii examined. This difference, in essence, is a measure of the influence of the LULC

TABlE 2. Greatest and least observed annual DTR $\left({ }^{\circ} \mathrm{C}\right)$, and associated classes, by climate region for the $100-\mathrm{m}$ radius predominant LULC analysis. The differences in the DTR were significant ( $\alpha=0.05$ ) for each climate region.

\begin{tabular}{|c|c|c|c|c|}
\hline \multirow{2}{*}{$\begin{array}{l}\text { Climate } \\
\text { region }\end{array}$} & \multicolumn{2}{|c|}{ Greatest DTR } & \multicolumn{2}{|c|}{ Least DTR } \\
\hline & Class & DTR & Class & DTR \\
\hline 1 & 5 & 16.8 & 9 & 8.2 \\
\hline 2 & 4 & 13.5 & 7 & 11.3 \\
\hline 3 & 4 & 12.8 & 7 & 10.6 \\
\hline 4 & 5 & 15.4 & 6 & 14.2 \\
\hline 5 & 4 & 14.0 & 3 & 11.6 \\
\hline 6 & 1 & 18.1 & 7 & 15.6 \\
\hline 7 & 6 & 18.1 & 1 & 15.7 \\
\hline 8 & 6 & 16.6 & 9 & 12.8 \\
\hline 9 & 4 & 17.8 & 1 & 14.7 \\
\hline 10 & 3 & 17.4 & 9 & 14.0 \\
\hline 11 & 5 & 16.7 & 7 & 15.2 \\
\hline 12 & 5 & 14.1 & 7 & 12.1 \\
\hline 13 & 9 & 14.0 & 8 & 12.0 \\
\hline 14 & 6 & 13.9 & 4 & 12.8 \\
\hline 15 & 6 & 12.7 & 9 & 11.2 \\
\hline 16 & 3 & 12.3 & 9 & 9.1 \\
\hline 17 & 5 & 12.8 & 8 & 11.0 \\
\hline 18 & 7 & 13.0 & 9 & 10.0 \\
\hline 19 & 6 & 14.0 & 3 & 12.5 \\
\hline 20 & 3 & 12.8 & 7 & 11.2 \\
\hline 21 & 6 & 13.6 & 7 & 12.6 \\
\hline 22 & 7 & 11.5 & 8 & 9.0 \\
\hline 23 & 3 & 12.5 & 9 & 9.3 \\
\hline
\end{tabular}


TABLE 3. Greatest and least observed DTR values $\left({ }^{\circ} \mathrm{C}\right)$, averaged over the climate regions, for the three radii and intervals.

\begin{tabular}{rccc}
\hline \hline Radius $(\mathrm{m})$ & Winter & Summer & Annual \\
\hline \multicolumn{4}{c}{ Greatest DTR } \\
100 & 12.9 & 16.0 & 14.5 \\
1000 & 12.9 & 16.0 & 14.6 \\
10000 & 12.7 & 16.2 & 14.3 \\
\multicolumn{4}{c}{ Least DTR } \\
100 & 10.3 & 12.9 & \\
1000 & 10.5 & 13.0 & 12.0 \\
10000 & 10.6 & 13.5 & 12.2 \\
\hline
\end{tabular}

classes on the DTR. The difference in the greatest and least observed DTR (DTR $\max _{\min }$ ) values varied from $1.9^{\circ}$ to $3.1^{\circ} \mathrm{C}$ (Table 4 ). The $t$ statistic in the MEANS procedure (SAS, 1990) was used to assess the significance of $\mathrm{DTR}_{\max -\min }$. The $\mathrm{DTR}_{\max -\min }$ were significant $(\alpha=.01)$ within each of the combinations of radii and intervals. The greatest annual DTR $\max _{\min }$ was observed for the LULC classes predominant within $100 \mathrm{~m}$ and the least for those within a radius of $10000 \mathrm{~m}$. Similar results were observed for the winter and summer data. The summer months displayed the greatest DTR $\max _{\min }$. This observation suggests that the predominant LULC classes may have a greater effect on DTR during the summer rather than winter.

\section{c. Land use/land cover influence on DTR}

The greatest observed annual DTR for the $100-\mathrm{m}$ radius analyses was primarily associated with those LULC classes that could be considered rural (farm, forest, and cities with populations $<10000)$. The forest (class 3), farm (class 4), small town (class 5), and town (class 6) LULC classes, when predominant within a radius of $100 \mathrm{~m}$, were associated with the greatest observed DTR more than $75 \%$ of the time ( Table 5). The relative frequency that these classes displayed the greatest (or least) DTR was compared to the frequency that these classes would have randomly displayed the greatest (or least) DTR. The $t$ statistic was used to determine if differences were significant. The

TABLE 4. Difference between the greatest (max, related to rura LULC) and least (min, related to urban LULC) winter, summer, and annual DTR. The DTR max $-\min _{\text {in }}$ were averaged over all climate regions. The observed differences were all significant $(\alpha=0.01)$.

\begin{tabular}{rccc}
\hline & \multicolumn{3}{c}{$\mathrm{DTR}_{\max -\min }\left({ }^{\circ} \mathrm{C}\right)$} \\
\cline { 2 - 4 } Radius (m) & Winter & Summer & Annual \\
\hline 100 & 2.6 & 3.1 & 2.5 \\
1000 & 2.4 & 3.0 & 2.4 \\
10000 & 2.1 & 2.7 & 1.9 \\
\hline
\end{tabular}

TABLE 5. Frequency that the greatest observed DTR was associated with a LULC class of forest, farm, small town, and town.

\begin{tabular}{rccc}
\hline & \multicolumn{3}{c}{ Relative frequency (\%) } \\
\cline { 2 - 4 } Radius (m) & Winter & Summer & Annual \\
\hline 100 & $90^{\mathrm{a}}$ & $77^{\mathrm{b}}$ & $83^{\mathrm{a}}$ \\
1000 & $95^{\mathrm{a}}$ & 75 & $80^{\mathrm{b}}$ \\
10000 & 69 & 78 & 72 \\
\hline
\end{tabular}

a Indicates significant at $\alpha=.01$.

${ }^{\mathrm{b}}$ Indicates significant at $\alpha=.05$.

frequency at which the greatest observed DTR was associated with a predominant LULC class of forest, farm, small town, or town was $90 \%, 77 \%$, and $83 \%$ for the winter, summer, and annual DTR, respectively (Table 5). The influence of these LULC classes on the DTR was not significant at the $10000-\mathrm{m}$ radius. The influence of these LULC classes on observation of the greatest DTR was most apparent in the winter and annual intervals.

The predominantly urban classes of small city, large city, and airport dominated the least observed DTR within the $100-\mathrm{m}$ and $1000-\mathrm{m}$ radii (Table 6 ). This result might be expected as the results of urban heat island analyses have indicated a decreased range of temperature associated with urban stations (Karl et al. 1988).

The frequency at which the least observed DTR was associated with a predominant LULC class of small city, large city, or airport within $100 \mathrm{~m}$ of the station was $81 \%, 73 \%$, and $74 \%$ for the winter, summer, and annual DTR, respectively (Table 6). The airport class was included in the urban group based on the DTR data. The airport class was associated with the least observed DTR more than 16 times as frequent as it was associated with the greatest observed DTR. Thus, in this analysis the data from observation stations located at or near airports displayed characteristics similar to those of the urban classes.

The results presented in Tables 5 and 6 would seem to indicate that the urban and rural LULC types are most highly associated with the observed DTR when predominant within a $100-\mathrm{m}$ radius of the observation

TABLE 6. Frequency that the least observed DTR was associated with a LULC class of small city, large city, or airport.

\begin{tabular}{cccc}
\hline & \multicolumn{3}{c}{ Relative frequency (\%) } \\
\cline { 2 - 4 } Radius (m) & Winter & Summer & Annual \\
\hline 100 & $81^{\mathrm{a}}$ & $73^{\mathrm{a}}$ & $74^{\mathrm{a}}$ \\
1000 & $65^{\mathrm{a}}$ & $65^{\mathrm{a}}$ & $65^{\mathrm{a}}$ \\
10000 & 31 & $56^{\mathrm{b}}$ & $50^{\mathrm{b}}$ \\
\hline
\end{tabular}

${ }^{\text {a }}$ Indicates significant at $\alpha=.01$.

${ }^{\mathrm{b}}$ Indicates significant at $\alpha=.05$. 
station. The association between the urban and rural LULC types and observed DTR remains present even at $10000 \mathrm{~m}$ (Table 6) although not as great as at 100 or $1000 \mathrm{~m}$.

Future changes in LULC may confound future investigations of the change in DTR over time (e.g., Karl et al. 1993). The DTR has been observed to decrease over the 1951-1990 interval in the United States (Karl et al. 1993). The same effect, a decrease in DTR, would be expected (Table 3 ) as the LULC associated with a station changed from predominantly rural (those stations that exhibit the greatest DTR) to urban (those that exhibit the least DTR).

The Karl et al. (1993) study used a subset of the stations included in this study that were selected to minimize inhomogeneities through the interval analyzed. Thus, the results observed by Karl et al. were unlikely due to changes in LULC at the stations used in their analysis. The results of this study, however, do indicate that a change in the predominant LULC from rural to urban could result in decreases in DTR. Karl et al. found a decrease in the annual DTR within the United States of $1.5^{\circ} \mathrm{C} / 100 \mathrm{yr}$. Future changes in the predominant LULC from rural to urban could result in decreases in the DTR (e.g., Table 4) greater than those observed by Karl et al. (1993). Thus, the changes in LULC at observation sites should be monitored as any variable that might introduce an inhomogeneity in the data record.

\section{Conclusions}

The results of this study suggest that significant differences in the climatological DTR were observed and could be attributed to the predominant land use/land cover associated with the observation stations. The results suggest that changes in the predominant land use/ land cover conditions, even within a 10000 -m radius of an observation station, can significantly influence the climatological DTR. Changes in the predominant LULC associated with observation sites should be monitored similar to the current practice of monitoring changes in instruments or time of observation at the observations sites.

Acknowledgments. We are grateful to Lewis France, Anne Viront-Lazar, Elaine Mason, Alvin McGahee, and Ken Weathers at the National Climatic Data Center, who where responsible for the land use/land cover survey of weather observation stations. We also wish to thank David Bowman for his assistance with data extraction. This research was partially funded by the U.S. Department of Energy through Interagency Agreement DE-AI05-90ER60952.

\section{REFERENCES}

Changnon, S. A., 1992: Inadvertent weather modification in urban areas: Lessons for global climate change. Bull. Amer. Meteor. Soc., 73, 619-627.

Gallo, K. P., A. L. McNab, T. R. Karl, J. F. Brown, J. J. Hood, and J. D. Tarpley, 1993: The use of NOAA AVHRR data for assessment of the urban heat island effect. J. Appl. Meteor., 32, 899-908.

Karl, T. R., H. F. Diaz, and G. Kukla, 1988: Urbanization: Its detection and effect in the United States climate record. J. Climate, 1, 1099-1123.

- C. N. Williams Jr., F. T. Quinlan, and T. A. Boden, 1990: United States Historical Climatology Network (HCN) serial temperature and precipitation data. Environmental Sciences Tech. Rep. 3404, 374 pp. [Available from National Technical Information Service, U. S. Dept. Commerce, 5285 Port Royal Rd., Springfield, VA 22161.]

_- and Coauthors, 1993: A new perspective on recent global warming: Asymmetric trends of daily maximum and minimum temperature. Bull. Amer. Meteor. Soc., 74, 1007-1023.

Kukla, G., J. Gavin, and T. R. Karl, 1986: Urban warming. J. Climate Appl. Meteor., 25, 1265-1270.

Landsberg, H. E., 1981: The Urban Climate. Academic Press, 275 $\mathrm{pp}$.

NOAA, 1996: 1990 Survey of predominant land use/land cover for the stations included in the US Historical Climatology Network. [Available on-line from http://www.ncdc.noaa.gov/ushen/ ushcn.html]

SAS, 1990: SAS Procedures Guide Version 6. 3d ed. SAS Institute, $705 \mathrm{pp}$.

WMO, 1990: Report of the expert group on global baseline datasets. WMO/TD-No. 359, $76 \mathrm{pp}$. [Available from World Meteorological Organization, Case postale 2300, CH-1211, Geneva, Switzerland.] 